\title{
Characterization of AM Fungal Isolates of Different Agro-Climatic Zones of Andhra Pradesh and Their Efficacy on Maize (Zea mays L) Plant Growth
}

\author{
K. Swarnalatha ${ }^{1}$, N. Trimurtulu ${ }^{2}$, K. Ammani ${ }^{1}$, R. Lakshmipathy ${ }^{2}$ and S. Ashok ${ }^{2}$ \\ ${ }^{1}$ Department of Botany and Microbiology, Acharya Nagarjuna University, Guntur, AP, India \\ ${ }^{2}$ ANGRAU, Agricultural Research Station, Amaravathi- 522020, Guntur Dt., AP, India \\ *Corresponding author
}

\section{A B S T R A C T}

\section{Ke y w o r d s \\ Rhizosphere soil, AM Spore morphology, Root colonization, Plant growth. \\ Article Info \\ Accepted: \\ 15 March 2017 \\ Available Online: \\ 10 April 2017}

\begin{abstract}
Arbuscular mycorrhizal fungi (AMF) form obligate symbiotic association with the roots of crop plants and play a critical role in enhancing plant growth under semi-arid climatic conditions. Present investigation has been taken up to characterize the isolated AM fungal species from rhizosphere soils of different host crops grown across various Zones of Andhra Pradesh. A total of twelve AM fungal spores were characterized based on their morphological traits. The Genus Glomus has been found to be most predominant in the soils of Andhra Pradesh and contributed to an extent of $75 \%$ of the total AM fungal genera studied in the present work. Growth of Maize crop was evaluated after inoculating 12 different AM Fungal isolates collected from five different agroclimatic Zones of Andhra Pradesh. These mycorrhizal isolates were tested for their ability to increase the plant growth. Among the twelve isolates root colonization was maximum where we inoculated with whereas AMF-C3 (78.8\%). Spore density was maximum in the rhizosphere soil of AMF-B3 (40.0/100g of soil) and plant height. Response of AMF isolates inoculation to maize plants with highest fresh biomass was recorded in the plants inoculated with AMFC3 (162.6g/plant), followed by AMF-B1 (139.4 g/plant) AMF-S2 (136.8g/plant). Similar trend was recorded with respect to plant dry mass in response to AMF isolates inoculation, where highest plant dry biomass was recorded in AMF-C3 (83.0 g/plant) and least in case of AMF-P2 (100.3 g/plant). Plants inoculated with AMF-C3 resulted in significant increase in per cent AMF root colonization, spore density, plant height and dry mass compared to the other AMF isolates.
\end{abstract}

\section{Introduction}

Arbuscular mycorrhizal fungi (AMF) are ubiquitous in nature and can contribute directly or indirectly for altering the soil physico-chemical properties along with biochemical and morphological properties of host plants. AM fungi are commonly occurring fungi that live in an obligate symbiotic status with the majority of crop plants (Smith and Read, 1997). There is a diverse distribution of these AM fungal spores in the soils of different agro-climatic situations. AM fungal association has a positive influence on plant growth, which is mainly attributes to the ability of AM fungi to take up nutrients from the soil (Barea et al., 2008) and deliver them to the roots of its host. All the AM fungal species may not directly affect the change of soil physico-chemical 
properties but the roots of host plant indirectly affect the aggregate stability by root mycorrhizal colonization and glomalin production (Bedini et al., 2009). Most studies of arbuscular mycorrhizal fungi during ecosystem development focus on abundance, particularly the extent of root infection, with few studies characterizing community composition. In the present study the characterization of AM fungal isolates obtained from different agro-climatic Zones of Andhra Pradesh from the rhizosphere soils of different host plants was studied and evaluated the effect of AM fungal isolates on maize crop growth.

\section{Materials and Methods}

\section{Collection and identification of AM Fungal spores}

Spores of AM fungi were collected from rhizosphere soil by the wet sieving and decanting technique (Gerdemann and Nicolson, 1983). One hundred grams of rhizosphere soil sample was taken and mixed thoroughly in 5.0 lts of forced tap water and allowed to settle down the heavier particles for a few seconds. The suspension was then decanted through the stack of sieves 500-0.25 $\mu \mathrm{m}$ (arranged in descending order of mesh size from top to bottom). Same process was repeated 6-8 times and the residue from each sieve was collected into Petri plates with little distilled water. Intact AM fungal spores were examined and counted under stereo microscope (Olympus OIC, 1629) and identifications were made by observing diagnostic characteristics such as spore wall, colour, size and type of hyphal attachment according to Schenck and Perez (1990).

\section{AM fungal inoculum preparation}

Pot experiment was conducted under green house conditions for a period of 60 days after inoculation to assess the effect of indigenous
AM fungal isolates on the growth of maize using sterile soil and sand mixer (1:2 ratio). Twelve AMF isolates, obtained from different Agroclimatic Zones of Andhra Pradesh were used for inoculum preparation. AM Fungal isolates were multiplied on maize plants under semi sterile conditions. Pots were filled with sterilized soil-sand mixer, 200 spores of each isolate were layered on the potting surface. Three seeds were sown on each pot. The pots were kept in green house under controlled environmental conditions and watered regularly. After 60 days, the crop was harvested by cutting maize plants to the root level. The root mass was separated from the pot and was chopped into small bits. The chopped root bits which were infected with mycorrhizal fungi were properly mixed in lignite carrier powder. After a week days inoculums strength was assessed by using MPN technique.

\section{Root colonization by AM Fungi}

Root segments were cut into $1-\mathrm{cm}$ bits and stained by the method of Phillips and Hayman (1970). The roots were cleared with $8 \%$ of $\mathrm{KOH}$ at $90^{\circ} \mathrm{c}$ for 10 minutes and Roots were then acidified with $1 \% \mathrm{HCl}$ and root bits were treated with $0.05 \%$ Trypan blue kept it for overnight, excess stain was removed with clear lactoglycerol. Root segments were mounted on glass slide with lactoglycerol and observed under microscope. A minimum of 100 segments for each samples were observed for the assessment of percentage colonization of AM fungi using the following formula.

$\%$ of $\mathrm{AM}$ colonization $=$

Total no. of root segments colonized $\mathrm{X} 100$

Total no. of root segments examined

\section{Estimation of fresh and dry weight}

After 60 days of growth of the plants was uprooted taking care not to damage the roots. 
The roots were washed in running water till the adhering soil particles were removed. The fresh weight of the root and shoot were recovered after removing the external moisture for both control and inoculated treatments. The root and shoot samples were oven dried for 72 hours at $70^{\circ} \mathrm{C}$. The dry weight of root mass was recorded until the constant weights were obtained.

\section{Results and Discussion}

Characterization of AM fungal spores obtained from rhizosphere soils of different field crops

A total number of 12 unique $\mathrm{AM}$ fungal spores were isolated from rhizosphere soils of four different agricultural crops i.e. Cotton, Sugarcane, Paddy and Black gram (Table 1). Three specific AM fungal isolates were characterized from each crop rhizosphere of different agroclimatic Zones of Andhra Pradesh as detailed below.

\section{Isolate $\mathrm{AMF}-\mathrm{C} 1$}

Oval in shape they are dark yellow in colour and $122 \mu \mathrm{m}$ in diameter. Number of spore wall are 2 and Spore wall size is $2 \mu \mathrm{m}$ and surface is rough and it contained one subtending hypha. Based on the specific morphological characters given by Schenck and Perez (1990) this isolate has been identified as G. multicaulis (Plate-1).

\section{Isolate AMF-C2}

Oval in shape they are Golden yellow in colour and $230 \mu \mathrm{m}$ in diameter. Spore wall number is 1 , spore wall size $5 \mu \mathrm{m}$ and surface is rough and it contains one subtending hypha. As per the morphological characters described by Schenck and Perez (1990) this isolate has been identified as $S$. calospora (Plate-1).

\section{Isolate AMF-C3}

Oval in shape they are yellow in colour and $90-115 \mu \mathrm{m}$ in diameter, spore wall number is 1 and Spore wall size $8.5 \mu \mathrm{m}$, surface is smooth and it contains 1 subtending hypha. Based on the specific morphological traits described by Schenck and Perez (1990) the isolate has been identified as G. fasciculatum (Plate-1).

\section{Isolate AMF-S1}

The spore is in oval shape and yellow in colour. The spore size is $145 \mu \mathrm{m}$ in diameter, spore wall number is 4 and Spore wall size 6 $\mu m$, surface is granular and it contains 1 subtending hypha. As per the specific morphological characters given by Schenck and Perez (1990) this isolate has been named as A. scrobiculata (Plate-1).

\section{Isolate AMF-S2}

The spore is globose in shape and orange in color. The spore size is $130 \mu \mathrm{m}$ in diameter, spore wall number is 2 and Spore wall size is $14 \mu \mathrm{m}$, surface is smooth and it contains 1 subtending hypha. As per the specific morphological characters given by Schenck and Perez (1990) this isolate has been identified as G. magnicaulis (Plate-1).

\section{Isolate AMF-S3}

The isolate AMF-S3 is in oval shape and yellow in lob. The size of the spore is $120 \mu \mathrm{m}$ in diameter, spore wall number is 3 and Spore wall size $8 \mu \mathrm{m}$. The spore surface is granular. The morphological characters described by Schenck and Perez (1990) perfectly matched to identify this isolate as G. nicolsoni (Plate$1)$.

\section{Isolate AMF-P1}

The spore of AMF-P1 is in ellipsoidal shape and yellow in colour. The size of the spore is 
$100-160 \mu \mathrm{m}$ in diameter, spore wall number is 3 . The spore wall size is $10 \mu \mathrm{m}$, surface is smooth and it contains 1 subtending hypha. As per the specific morphological characters given by Schenck and Perez (1990) this isolate has been identified as $G$. fulvum (Plate-1).

\section{Isolate AMF-P2}

The isolate AMF-P2 spore is in oval shape. These spores are in brown colour and 80-100 $\mu m$ in diameter, spore wall number is 2 and Spore wall size is $9 \mu \mathrm{m}$. The spore surface is dark granular and it contains 1 subtending hypha. As per the specific morphological characters given by Schenck and Perez (1990) this isolate has been identified as $G$. intraradices (Plate-1).

\section{Isolate AMF-P3}

AMFP3 spores are in oval shape and they are hyaline with $120 \mu \mathrm{m}$ in diameter. Spore wall number is 4 and spore wall size $7 \mu \mathrm{m}$, and surface is granular. According to taxonomic characters mentioned by Schenck and Perez (1990) this isolate has been identified as $G$. lacteum (Plate-1).

\section{Isolate AMF-B1}

The isolate AMF-B1 has globose shaped spores and they are yellow in colour. The size of the spore is $145 \mu \mathrm{m}$ in diameter, spore wall number is 2 and Spore wall size is $8 \mu \mathrm{m}$. The surface of the spore is granular and it contains 1 subtending hypha. As per the specific morphological characters given by Schenck and Perez (1990) this isolate has been identified as G. leptotichum (Plate-1).

\section{Isolate AMF-B2}

The spore of AMF-B2 is in ellipsoidal in shape. These spores are in brown-reddish in colour and 90-160 $\mu \mathrm{m}$ in diameter, spore wall number is 2 and spore wall size $11 \mu \mathrm{m}$, surface is smooth and it contains 2 subtending hyphae. As per the specific morphological characters given by Schenck and Perez (1990) this isolate has been identified as $G$. radiatum (Plate-1).

\section{Isolate AMF-B3}

AMF-B3 isolate has globose shape and they are yellow in colour with $120 \mu \mathrm{m}$ in diameter. The spore wall number is 2 and Spore wall size is $7 \mu \mathrm{m}$ with smooth surface. The spore contained one subtending hypha. These specific morphological features were tallied with $G$. phansihalos (Plate-1) as reported by Schenck and Perez (1990). A number of 12 isolates were identified up to the species level based on the morphological characteristics described by Schenck and Perez (1990). Out of 12 isolates $G$. multicaulis (AMF-C1), $S$. calospora (AMF-C2), and G. fasciculatum (AMF-C3) were collected from Cotton rhizosphere, A. scrobiculata (AMF-S1), G. magnicaulis (AMF-S2), and A. nicolsoni (AMF-S3) from Sugarcane rhizoshere, $G$. fulvum (AMF-P1), G. intraradices (AMF-P2) and $G$. lacteum (AMF-P3) from Paddy rhizosphere, $G$. leptotichum (AMF-B1), $G$. radiatum (AMF-B2) and $G$. phansihalos (AMF-B3) from Black gram rhizosphere. This is in support with the finding of Chaurasia (2001) that the distribution and abundance of AM fungi vary greatly among different sites i.e. natural and manmade ecosystems. Among the twelve isolates Glomus was more predominant genus $(75 \%)$ followed by Acaulospora and Scutellospora. Earlier taxonomic efforts to characterize arbuscular mycorrhizal fungal communities were based largely on spore morphology, with many species also grouped under the genus Glomus (Herrera-Peraza et al., 2011). Natural soil offers consortium of indigenous mycorrhizal fungi and often used as source of inoculum. 
Table.1 Morphological characters of AM Fungal isolates obtained from different agricultural crops

\begin{tabular}{|c|c|c|c|c|c|c|c|c|c|}
\hline S.No & $\begin{array}{l}\text { Isolate } \\
\text { code }\end{array}$ & Shape & $\begin{array}{l}\text { Spore } \\
\text { Size } \\
(\mu \mathrm{m})\end{array}$ & Colour & $\begin{array}{c}\text { Spore wall } \\
\text { size }(\mu \mathrm{m})\end{array}$ & $\begin{array}{c}\text { No. of } \\
\text { Spore walls }\end{array}$ & $\begin{array}{c}\text { Spore } \\
\text { surface }\end{array}$ & $\begin{array}{c}\text { No. of } \\
\text { subtending } \\
\text { hyphae }\end{array}$ & Probable genus \\
\hline 1 & AMF-C1 & Oval & 122 & Dark yellow & 9 & 2 & Rough & 1 & G.multicaulis \\
\hline 2 & AMF-C2 & Oval & 230 & Golden Yellow & 5 & 1 & Rough & 1 & S.calospora \\
\hline 3 & AMF-C3 & Oval & $90-115$ & Yellow & 8.5 & 1 & Smooth & 1 & G.fasciculatum \\
\hline 4 & AMF-S1 & Oval & 145 & Yellow & 6 & 4 & Granular & - & A.scrobiculata \\
\hline 5 & AMF-S2 & Globose & 130 & Orange & 14 & 2 & Smooth & 1 & G.magnicaulis \\
\hline 6 & AMF-S3 & Oval & 120 & Yellow & 8 & 3 & Granular & - & A.nicolsoni \\
\hline 7 & AMF-P1 & Ellipsoidal & $100-160$ & Yellow & 10 & 3 & Smooth & 1 & G.fulvum \\
\hline 8 & AMF-P2 & Oval & $80-100$ & Brown & 9 & 2 & $\begin{array}{c}\text { Dark } \\
\text { granular }\end{array}$ & 1 & G.intraradices \\
\hline 9 & AMF-P3 & Oval & 125 & Hyaline & 7 & 4 & Granular & - & G.lacteum \\
\hline 10 & AMF-B1 & Globose & 145 & Yellow & 8 & 2 & Granular & 1 & G.leptotichum \\
\hline 11 & AMF-B2 & Ellipsoidal & $90-160$ & Brown-reddish & 11 & 2 & Smooth & 2 & G.radiatum \\
\hline 12 & AMF-B3 & Globose & 120 & Yellow & 7 & 2 & Smooth & 1 & G.phansihalos \\
\hline
\end{tabular}


Table.2 Competitive ability of AM fungal isolates for root colonization and sporulation in maize

\begin{tabular}{|c|c|c|}
\hline Treatment & $\begin{array}{c}\text { Root colonization (\%) } \\
\text { at 50\% silky stage }\end{array}$ & AMF spores /100g soil \\
\hline AMF-C1 & 67.2 & 27.6 \\
\hline AMF-C2 & 48.6 & 28.0 \\
\hline AMF-C3 & 78.8 & 39.0 \\
\hline AMF-S1 & 61.4 & 32.6 \\
\hline AMF-S2 & 68.0 & 35.4 \\
\hline AMF-S3 & 42.8 & 30.2 \\
\hline AMF-P1 & 40.8 & 31.8 \\
\hline AMF-P2 & 41.7 & 30.5 \\
\hline AMF-P3 & 35.0 & 31.3 \\
\hline AMF-B1 & 53.6 & 38.6 \\
\hline AMF-B2 & 42.4 & 33.2 \\
\hline AMF-B3 & 64.0 & 40.0 \\
\hline CONTROL & 24.0 & 22.8 \\
\hline CV & 14.75 & $14.99 \%$ \\
\hline SE & 3.38 & 2.17 \\
\hline CD at 5\% & 8.266 & 5.637 \\
\hline
\end{tabular}

Table.3 Effect of inoculation of AM fungal isolates on plant growth parameters of Maize crop

\begin{tabular}{|c|c|c|c|}
\hline \multirow{2}{*}{ Treatment } & Plant height (cm) & \multicolumn{2}{|c|}{ Plant biomass } \\
\cline { 3 - 4 } & & $\begin{array}{c}\text { Fresh biomass } \\
\text { (g/plant) }\end{array}$ & $\begin{array}{c}\text { Dry biomass } \\
\text { (g/plant) }\end{array}$ \\
\hline AMF-C1 & 98.5 & 134.2 & 63.2 \\
\hline AMF-C2 & 91.1 & 124.9 & 58.6 \\
\hline AMF-C3 & 103.6 & 162.6 & 83.0 \\
\hline AMF-S1 & 102.1 & 127.9 & 64.1 \\
\hline AMF-S2 & 96.7 & 136.8 & 68.7 \\
\hline AMF-S3 & 101.6 & 107.1 & 52.5 \\
\hline AMF-P1 & 111.5 & 110.5 & 57.3 \\
\hline AMF-P2 & 120.8 & 100.3 & 49.5 \\
\hline AMF-P3 & 102.2 & 103.2 & 47.3 \\
\hline AMF-B1 & 106.8 & 139.4 & 72.1 \\
\hline AMF-B2 & 109.9 & 103.0 & 57.7 \\
\hline AMF-B3 & 128.1 & 142.8 & 75.5 \\
\hline CONTROL & 84.8 & 83.8 & 36.5 \\
\hline CV & 15.24 & 17.82 & 14.71 \\
\hline SE & 7.10 & 9.67 & 3.98 \\
\hline CD at 5\% & 19.685 & 27.261 & 11.458 \\
\hline
\end{tabular}


Plate.1 Morphological structures of the different spores obtained from rhizosphere soils of field crops

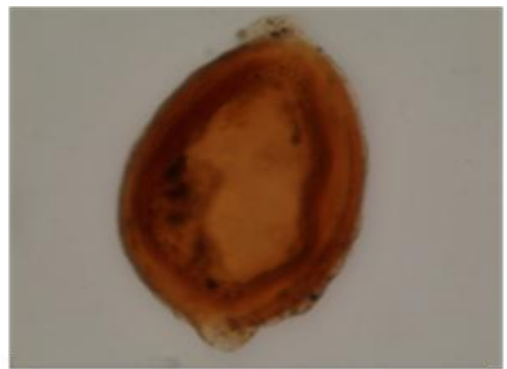

G.multicaulis

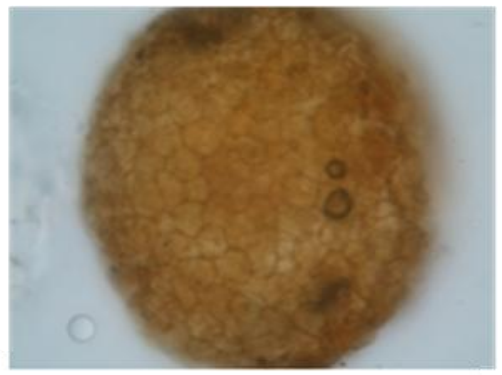

A.scrobiculata

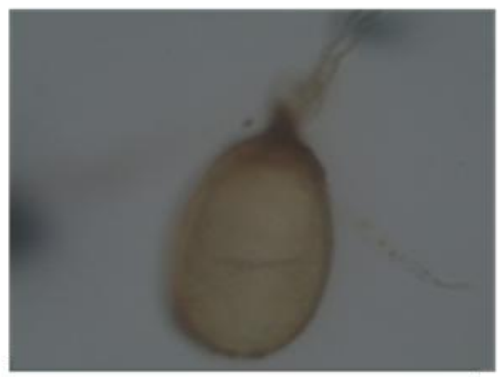

G. fulvum

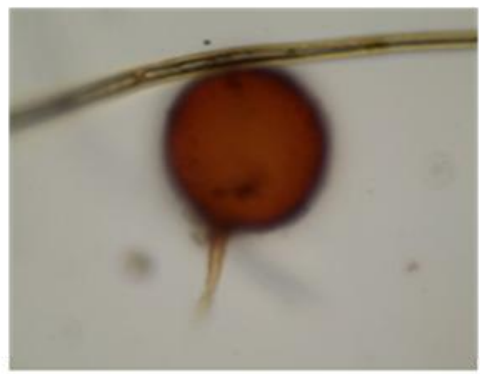

G.leptotichum

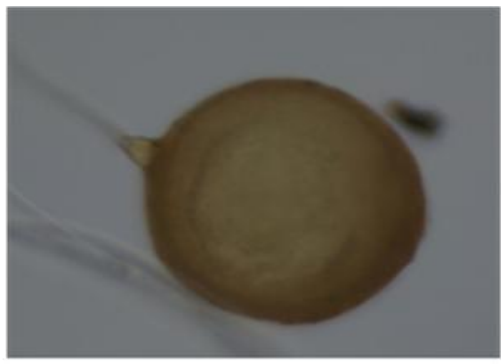

S.calospora

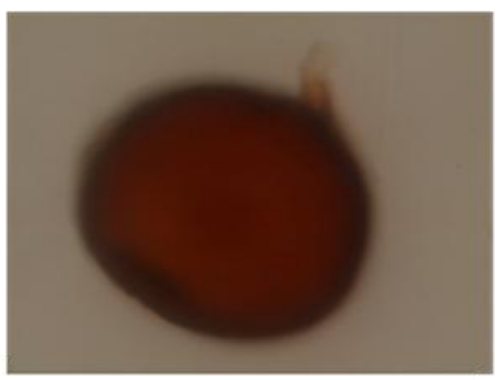

G.magnicaulis

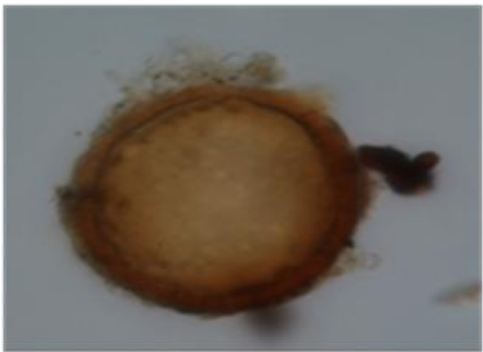

G.intraradices

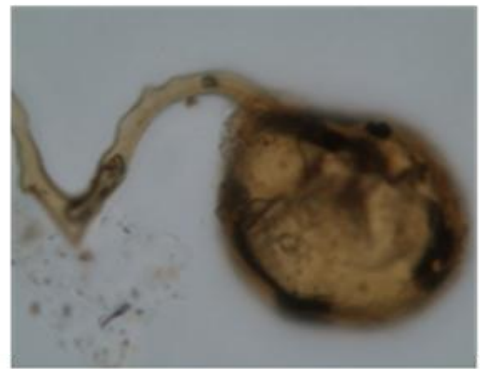

G.radiatum

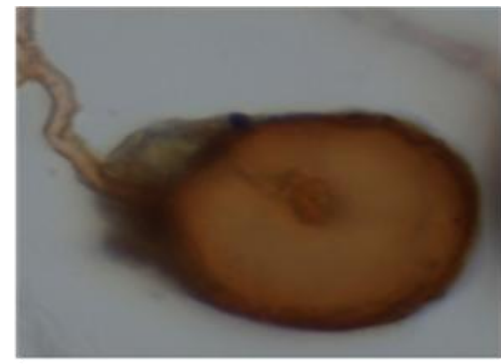

G.fasciculatum

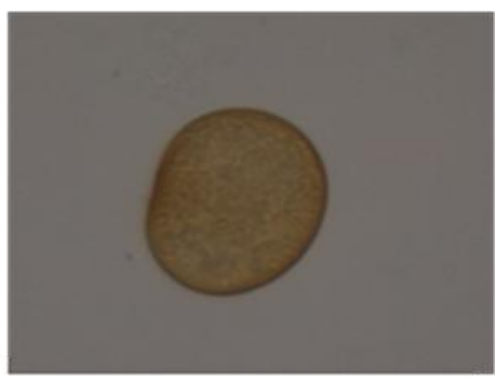

A.nicolsoni

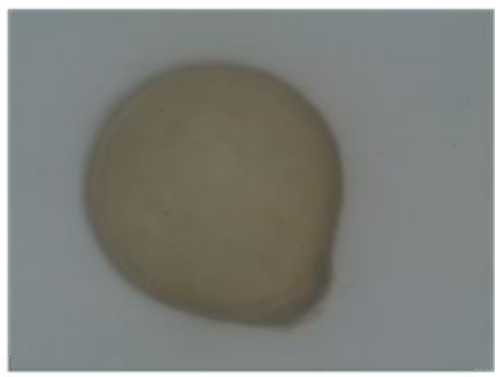

G.lacteum

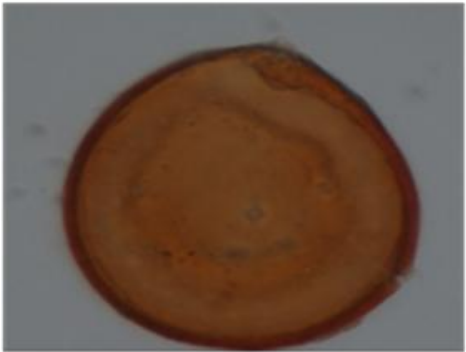

G.phansihalos 
Consistency of response to inoculation with selected AM fungal strains is a prerequisite to adoption of AM inoculation practices in plant production. In the pot culture experiment all the collected AM fungal isolates were thoroughly screened against maize crop for their efficacy on plant growth promotion. AM fungal isolates colonized maize plants to a varying degree. Among different AM fungi, plant roots inoculated with AMFC3: $G$. fasciculatum (Table 2) was colonized significantly high per cent $(78.8 \%)$ followed by AMF-S2 (68.0\%). In general colonization is one of the important parameter to evaluate the efficiency of the strain competitiveness in the rhizo-microcosma of the host plant. Spore number in the rhizosphere soil was maximum in the plants inoculated with AMF-B3 (40.0/100g of soil) at 45 days after sowing. Several other researchers also reported that different AM strains have different ability to function in different soil environments as shown by different AM fungal community composition (Fitzsimons et al., 2008), development (Abbott and Robson, 1991), sporulation (Baum et al., 2002), and function (Karasawa et al., 2001) in different soils. Similar way in the present study, AM Fungi differed in their ability to promote plant growth. Significantly highest plant height was in the plants inoculated with $\mathrm{AMF}$ isolate AMF-B3 $(128.1 \mathrm{~cm})$. Highest fresh biomass was recorded in the plants inoculated with AMF-C3 (162.6g/plant), followed by AMFB1 (139.4 g/plant) AMF-S2 (136.8g/plant) AMF-C1 (134.2g/plant) (Table 3). The reliability of highly effective AM fungal strains seemingly depends on their ability to function under the soil conditions where they are introduced. Thakur and Panwar (1995) has reported that the AMF inoculation increased the root, shoot and total dry matter production in Mungbean. Udaiyan and Sugavanam (1996) reported that inoculation of Glomus fasciculatum with plants of Casuarina equisetifolia, results in the higher growth and biomass. Mudalagiriyappan et al., (1997) analyzed that AMF inoculation significantly increased in dry matter production, improved growth rate and net assimilation rate. Ubiquitous occurrence and importance of AM fungi for plant growth is now a well established fact by present results. Further, the beneficial use of AM inoculum in agriculture and raising nurseries has been reported by several researchers (Muthukumar et al., 2001; Smith and Read, 1997). The choice of effective AM fungal strains based on soil properties may be the corner stone for the development of effective use of AM inoculants in crop production.

In conclusion AM fungi are wide spread and form a symbiotic association with large group of plant species, and effectively improve growth. In the present study a range of genera were collected from different host crop rhizosphere soils and characterized at species level. Inoculation of AM fungal isolates showed a positive influence on AMF root colonization, spore population, host plant growth traits like plant height and biomass production. It was the indication for introducing AM fungi as a potential biofertilizer for enhancing crop growth and nutrient uptake.

\section{References}

Abbott, L.K., and A.D. Robson. 1991. Factors influencing the occurrence of vesiculararbuscular mycorrhizas. Agri. Ecosystems Environ., 35(2-3): 121-150

Barea, J.M., Ferrol, N., and Azcon-Aguilar, C and Azcon, R. 2008. Mycorrhizal symbioses. In the Eco-physiology of Plant-Phosphorous interactions pp. 143163, Springer Netherlands.

Baum, C., Weih, M., Verwijst, T., Makeschin, F. 2002. The effects of nitrogen fertilization and soil properties on mycorrhizal formation of Salix viminalis. Forst. Ecol. Manag., 160: 35-43. 
Bedini, S., Pellegrino, E., Avio, L., Pellegrini, S., Bazzoffi, P., Argese, E., and Giovannetti, M. 2009. Changes in soil aggregation and glomalin-related soil protein content as affected by the arbuscular mycorrhizal fungal species Glomus mosseae and Glomus intraradices. Soil Biol. Biochem., 41: 1491-1496.

Chaurasia, B. 2001. Ecological study of tropical forest trees with special reference to vesicular arbuscular mycorrhiza (VAM) association. Dis. Ph.D thesis. Dr. H. S. Gour, university, Sagar, M.P. India, 172pp.

Fitzsimons, M.S., Miller, R.M., Jastrow, J.D. 2008. Scale-dependent niche axes of arbuscular mycorrhizal fungi. Oecologia, 158: 117-127.

Gerdemann, J.W. and Nicolson, T.H. 1963. Spores of Mycorrhizal Endogone species extracted from soil by wet sieving and decanting. Trans. Br. Mycol. Soc., 46: 235-244.

Karasawa, T., Kasahara, Y., Takebe, M. 2001. Variable response of growth and arbuscular mycorrhizal colonization of maize plants to preceding crops in various types of soils. Biol. and Fertil. Soils, 33: 286-293.

Mudalagiriyappan, C.A., Agasimani, K.K., Veeranna, S. and Najappa, H.V. 1997. Nutrient recovery and balance sheet of nitrogen and phosphorus as influenced by sources of phosphate solubilizers and phosphate on groundnut. Mysore J. Bot., 32: 143-148.

Muthukumar. T., Udayan, K. and
Rajeshkannan, V. 2001. Response of neem (Azadiracta indica A. Juss) to indigenous arbuscular mycorrhizal fungi, phosphate solubilizing and symbiotic nitrogen fixing bacteria under tropical nursery conditions. Biol. Fertil. Soils, 34: 417-426.

Phillips, J.F. and Hayman, D.S. 1970. Improved procedures for clearing and staining parasites and vesicular arbuscular Mycorrhizal fungi for rapid assessment of infection, Trans. Br. Mycol., Soc., 55: 158-161.

Ricardo, A., Herrera-Peraza, Chantal Hamel, Félix Fernández, Roberto, L., Ferrer and Eduardo Furrazola. 2011. Soil-strain compatibility: the key to effective use of arbuscular mycorrhizal inoculants, Mycorrhiza, 21: 183-193

Schenck, N.C. and Perez, Y. 1990. Manual for the identification of VA Mycorrhizal fungi (vol.286) Gainesville: Synergistic publications.

Smith, S.A. and Read, D.J. 1997. Mycorrhizal symbiosis. 2 ed. Academic press London, $605 p$.

Thakur, A.K. and Panwar, J.D.S. 1995. Effect of Rhizobium VAM interactions on growth and yield in mungbean (Vigna radiata (L.) Wilczek) under field conditions Indian J. Plant. Pathol., 38: 62-65.

Udaiyan, K. and Sugavanam, V. 1996. Interaction of arbuscular mycorrhizal fungi and Frankia spp.On Growth and nutrient uptake in Casuarina equisetifolia Forst. Mycorrhizal: Biofertilizers for the Future, 230-237.

\section{How to cite this article:}

Swarnalatha, K., N. Trimurtulu, K. Ammani, R. Lakshmipathy and Ashok, S. 2017. Characterization of AM Fungal Isolates of Different Agro-Climatic Zones of Andhra Pradesh and Their Efficacy on Maize (Zea mays, L) Plant Growth. Int.J.Curr.Microbiol.App.Sci. 6(4): 17781786. doi: https://doi.org/10.20546/ijcmas.2017.604.213 